\title{
Two Factor Authentication Berbasis SMS pada Layanan Single Sign-On Universitas Mataram
}

\author{
SMS Based Two Factor Authentication in Mataram University's \\ Single Sign-On Service
}

\author{
Ahmad Zafrullah Mardiansyah*, Ariyan Zubaidi, \\ I Gde Putu Wirarama Wedaswhara W., Andy Hidayat Jatmika \\ Dept Informatics Engineering, Mataram University \\ Jl. Majapahit 62, Mataram, Lombok NTB, INDONESIA \\ Email: zaf@unram.ac.id, [zubaidi13,wirarama, andy]@unram.ac.id
}

\section{"Penulis korespondensi}

\begin{abstract}
Security is an important part of electronic transactions. Information systems at Mataram University are generally using the conventional username and password fields to authenticate the user (Single Factor Authentication - SFA). The SFA method is vulnerable to brute force attacks, especially to the Single Sign-On (SSO) service. To prevent brute force attacks, this study proposes an implementation of SMS-based Two Factor Authentication (TFA) toward SSO. This study found that the tests carried out by analyzing the simulation of brute force attacks, attackers could not obtain access to the user accounts. Another test done by the User Experience Questionnaire (UEQ) method found the score on the Pragmatic aspect was 1.927 (Excellent), on the Hedonic aspect it was 1.667 (Excellent), and overall was 1.797 (Excellent). Additional positive value comes from users who feel the features can help support the utilization of SSO. The reduction comes from users who feel they are not motivated enough to take advantage of TFA.
\end{abstract}

Key words: two factor authentication, single sign-on, user experience questionnaire, sms gateway

\section{PENDAHULUAN}

Keamanan menjadi kebutuhan pokok dalam melakukan transaksi secara elektronik. Sistem Informasi di lingkungan Universitas Mataram secara umum menyediakan model autentikasi terhadap pengguna berupa username dan password. Sistem melakukan autentikasi dengan mencocokkan kombinasi username dan password pengguna yang ada didalam database sehingga mampu menentukan apakah pengguna dapat diberikan akses atau tidak. Model autentikasi seperti ini juga sering disebut dengan Single Factor Authentication (SFA) [1].

Pada saat implementasi di dalam sistem, password pengguna tidak disimpan sebagai plain-text biasa. String password lebih sering disimpan dalam bentuk hash, yakni metode enkripsi dengan skema satu arah. Artinya string password yang telah di-hash tidak dapat diketahui nilai aslinya [2].

Dari sisi sistem, SFA memiliki beberapa kelebihan bagi pengguna. Di antaranya adalah mudah untuk diimplementasikan, tidak membutuhkan perlengkapan khusus untuk dapat dijalankan, dan mudah untuk menyediakan fasilitas lupa password. Bagi pengguna SFA memiliki beberapa celah keamanan yang umum terjadi, di antaranya pasword sangat memungkinkan untuk dilihat oleh orang lain yang ada dibelakang pengguna dan tingkat keamanan sangat bergantung pada kekuatan password (karakter spesial, panjang karakter, dan kombinasi karakter).

Secara psikologis, pengguna cenderung akan menggunakan string password yang mudah diingat. Kombinasi karakter agar menjadi sebuah kata yang mudah diingat akan menjadi terbatas. Dengan perkembangan teknologi saat ini beberapa penyedia dapat meng-generate kombinasi string yang memiliki kemungkinan cukup besar untuk digunakan sebagai password oleh kebanyakan pengguna. Daftar kombinasi string password tersebut lebih sering dikenal sebagai word-lists.

Masalah keamanan yang sering terjadi pada SFA adalah terkena serangan brute force. Brute force dilakukan dengan melakukan percobaan kombinasi username dan password yang sudah dimiliki dalam word-lists sampai mendapatkan response "true" dari sesi login. Brute force dilakukan secara otomatis oleh program, dengan membaca dan mengirim kombinasi username dan password setiap interval waktu tertentu [2], [3].

Teknik serangan brute force menggunakan pendekatan yang berbeda dengan serangan teknik lainnya. Brute force tidak perlu melakukan decrypt (de-hash) nilai string dari password pengguna yang ada pada database. Namun fokus utama brute force adalah mengumpulkan daftar kombinasi username dan password untuk dimasukkan kedalam pustaka word-lists.

Mempertimbangkan masalah yang sering kali terjadi pada model SFA, model pengamanan autentikasi tambahan yang diusulkan dalam penelitian ini adalah two factor authentication (TFA). TFA merupakan tahapan verifikasi tambahan yang diberikan setelah melalui SFA. TFA menuntut pengguna untuk membuktikan bahwa yang memasukkan username dan password tersebut memang betul pengguna yang bersangkutan. Pembuktian atau verifikasinya dilakukan dengan mengirim sebuah kode kepada pengguna sesaat setelah pengguna berhasil 
melakukan autentikasi menggunakan username dan password [4]-[6].

Salah satu media autentikasi tambahan untuk TFA adalah berbasis SMS. Kode autentikasi (token) dikirim secara otomatis oleh sistem sesaat setelah autentikasi username dan password kepada pengguna. Token ini yang nanti harus dimasukkan pengguna kedalam sistem untuk memastikan bahwa pengguna yang bersangkutanlah yang sedang melakukan transaksi, bukan orang yang lainnya. TFA berbasis SMS saat ini telah banyak digunakan oleh bank untuk membantu sistem memastikan keaslian transaksi dari pengguna. Dengan begitu pihak bank dapat meminimalisir kemungkinan terjadinya pencurian saldo nasabah [7].

Tingkat penetrasi pengguna smartphone dengan fasilitas SMS saat ini cukup tinggi. Smartphone terkini secara default telah dibekali dengan fasilitas SMS. Hal ini membuat implementasi TFA berbasis SMS menjadi lebih mudah untuk direalisasikan [8].

Dari segi keamanan, implementasi TFA dapat membantu sistem untuk memastikan keaslian dari autentikasi pengguna dari percobaan serangan yang mungkin dapat terjadi. Namun dari segi user experience (UX), tambahan tahapan dalam proses autentikasi akan membuat pengguna merasa sedikit kesulitan. Untuk itu pada penelitian ini, akan diimplementasikan TFA terhadap Single Sign-On (SSO) yang ada pada sistem-sistem di lingkungan Universitas Mataram untuk meningkatkan keamanan sistem serta melakukan analisa terhadap dampak UX yang terjadi di sisi pengguna [9], [10].

\section{TINJAUAN PUSTAKA}

Beberapa penelitian terkait telah dilakukan diantaranya adalah [8], [11] yang meningkatkan sistem keamanan menggunakan skema One Time Password (OTP). Skenario autentikasi dengan menggunakan OTP memanfaatkan fasilitas SMS yang dikirimkan kepada nomor pengguna. OTP yang dikirimkan di-generate dengan perhitungan matematis untuk memastikan kombinasi username, password, dan OTP tidak mudah ditebak. Pengujian yang dilakukan menghasilkan dua kesimpulan, yang pertama adalah peningkatan dari segi keamanan. Dan hasil pengujian kedua adalah ditemukan bahwa beban komputasi untuk implementasi sistem keamanan OTP menjadi lebih besar.

Pemanfaatan lapisan tamabahan untuk keamanan menjadi perhatian penting untuk perencanaan dan pengembangan sistem kedepannya. Tingkat keamanan dan metode autentikasi yang dapat digunakan oleh pengguna dianalisa oleh penelitian yang dilakukan [12]. Penelitian tersebut memberikan preferensi kepada pengguna untuk bebas menggunakan metode autentikasi yang diinginkan, sesuai dengan tingkat pemahaman terhadap IT. Dengan begitu pengembang melakukan identifikasi titik lemah kemamanan dari sebaran pengguna ada dibagian yang mana.

Implementasi TFA lainnya yang menggunakan skenario OTP yang dilakukan oleh [13] adalah menggunakan Global Positioning System (GPS). Penggunaan GPS dapat menambah tahapan proses autentikasi yang dilakukan oleh pengguna. Mulai dari kombinasi username dan password, sistem memeriksa lokasi pengguna, dan kemudian yang terakhir adalah mengirimkan OTP melalui SMS. Dari percobaan dan analisa yang dihasilkan, penelitian tersebut dapat meningkatkan sistem keamanan dengan meminimilasir kemungkinan dari terkena serangan brute force.

Penelitian lain terkait OTP dilakukan oleh [7]. Penelitian tersebut melakukan peningkatan keamanan dengan melakukan hash pada kode unik yang dikirimkan melalui SMS. Peneliti dalam penelitian tersebut menunjukkan kemungkinan kode OTP yang dikirim kepada pengguna dapat diketahui oleh penyerang menggunakan beberapa teknik serangan. Untuk itu dengan perhitungan matematis, kode OTP yang dikirimkan dilakukan hash menggunakan kombinasi dari beberapa isian data pengguna dan waktu sistem. Pengujian yang dilakukan menghasilkan kode OTP yang tidak pernah sama antar waktu sehingga disimpulkan bahwa kode OTP memiliki kemungkinan yang sangat kecil untuk dapat diketahui oleh penyerang.

Proses OTP umumnya dilakukan melalui SMS. Penelitian [14] menjelaskan masalah keamanan yang masih mungkin terjadi jika OTP dikirimkan melalui protocol SMS standar. Protocol SMS standar memungkinkan untuk dilihatnya isi pesan ketika pesan sedang dikirim atau diterima. Penelitian tersebut mengembangkan lapisan keamanan tambahan dengan menambahkan model enkripsi terhadap isi SMS, sehingga menjamin isi dari SMS tidak dapat terbaca dengan mudah meskipun jalur komunikasinya dapat ditembus.

\section{Metodologi Perancangan}

Penelitian ini merupakan tahap awal dari keseluruhan penelitian yang akan dilakukan. Pada tahun ini, penelitian berfokus pada identifikasi kebutuhan-kebutuhan yang diperlukan oleh Universitas Mataram yang kemudian akan disusun menjadi satu arsitektur yang menjelaskan informasi dan layanan apa yang akan dimasukkan, teknologi-teknologi yang digunakan, basis data yang dibutuhkan dan skema autentikasi yang dapat meningkatkan keamanan dari sisi pengguna.

Tahapan berikutnya adalah membangun sistem SMS Gateway yang berperan utama dalam membaca dan mengirimkan SMS kepada pengguna secara otomatis. Berikutnya adalah tahapan implementasi SMS token dengan sistem SSO di Universitas Mataram. Peta jalan penelitian dapat dilihat pada Gambar 1.

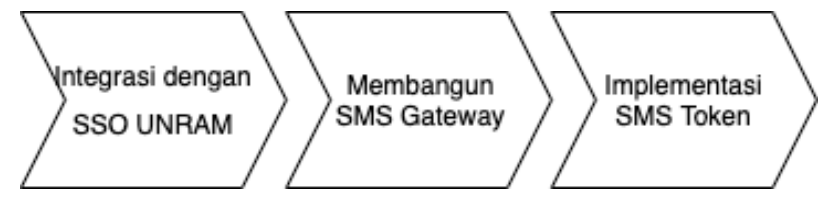

Gambar 1. Peta alur perancangan 


\section{A. Arsitektur Sistem}

Dalam implementasinya, secara keseluruhan sistem TFA berkomunikasi dengan beberapa sistem lainnya. Dalam lingkungan kampus Universitas Mataram pengelolaan akun SSO berpusat pada Sistem Informasi Akademik (SIA), sedangkan layanan SSO sendiri berada pada host dan sistem yang terpisah. Kemudian terdapat tambahan sistem SMS Gateway yang akan membantu dalam proses pengiriman token melalui SMS.

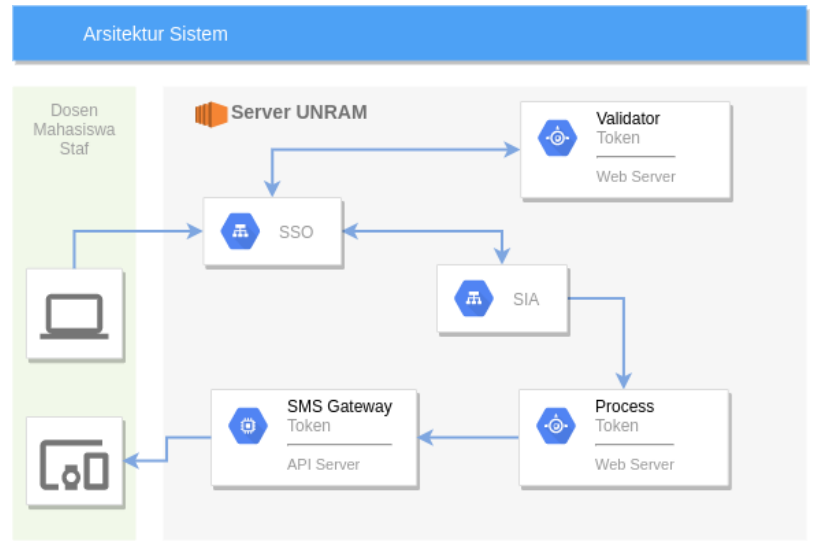

Gambar 2. Arsitektur sistem

Untuk melakukan proses login, setiap sistem yang telah terintegrasi di Universitas Mataram akan diarahkan ke halaman SSO. Sistem SSO merupakan interface untuk melakukan login dan reset password. Sistem SSO juga menjamin beberapa keamanan standar yang umum terjadi, beberapa diantaranya adalah menjaga integritas isian yang dimasukkan dan memberikan token pada setiap sesi login untuk menjaga sistem dari serangan brute force.

Sistem SSO bergantung pada SIA untuk proses autentikasi, karena semua data credentials dosen dan mahasiswa tetap tersimpan di SIA. SSO berkomunikasi dengan SIA menggunakan layanan API. Untuk saat ini semua aktivitas update data pribadi dan password dilakukan pada aplikasi SIA, termasuk pengaturan untuk mengaktifkan TFA terdapat pada SIA.

Setiap terjadi proses login, SIA akan memeriksa pengaturan dari pengguna yang sedang melakukan login. Ketika pengguna telah berhasil ter-autentikasi (memasukkan username dan password yang benar) pada SSO, SIA akan membuka data pengaturan pengguna untuk TFA. Jika pengaturan TFA pada pengguna diaktifkan, SIA akan melakukan generate token untuk digunakan sebagai validator dan disimpan secara sementara pada Session.

Pada saat pengguna memiliki token yang telah digenerate dan telah disimpan kedalam Session, berikutnya adalah SIA akan melakukan proses persiapan pengiriman token tersebut melalui SMS. Token tidak dikirim langsung oleh SIA, melainkan SIA adalah merupakan sebuah perantara. Dalam hal ini pengiriman token dilakukan dengan memanfaatkan sistem SMS Gateway, berikutnya setelah token berhasil dikirim melalui SMS halaman SIA pengguna akan otomatis dialihkan ke halaman TFA.
Lama waktu pengiriman token melalui SMS bergantung pada kondisi dan provider yang digunakan, dimana hal ini tidak dibahas dalam penelitian ini. Ketika pengguna telah menerima token melalui SMS, pengguna dapat memasukkan token yang telah diterima dari SMS tersebut pada isian TFA yang telah disediakan. Token yang telah dimasukkan kemudian akan dilakukan proses validasi, yakni akan dibandingkan dengan token yang sama yang sebelumnya telah tersimpan dalam Session login pengguna.

Jika token berhasil divalidasi maka pengguna akan diteruskan ke halaman yang dituju, seperti SIA atau sistem lain yang telah terintegrasi dengan SSO.

\section{B. Data Flow Diagram}

Secara umum alur komunikasi data dalam arsitektur TFA pada SSO melibatkan tiga komponen, yakni client, SSO, dan SMS Gateway. Pada sisi client, pengguna hanya perlu memasukkan username dan password akun SSO. Berikutnya SSO akan memeriksa status TFA pada akun SSO pengguna bersangkutan, jika fitur TFA diaktifkan maka SSO akan meng-generate sebuah token yang nantinya akan dikirimkan kepada pengguna melalui komponen ketiga, yakni SMS gateway.

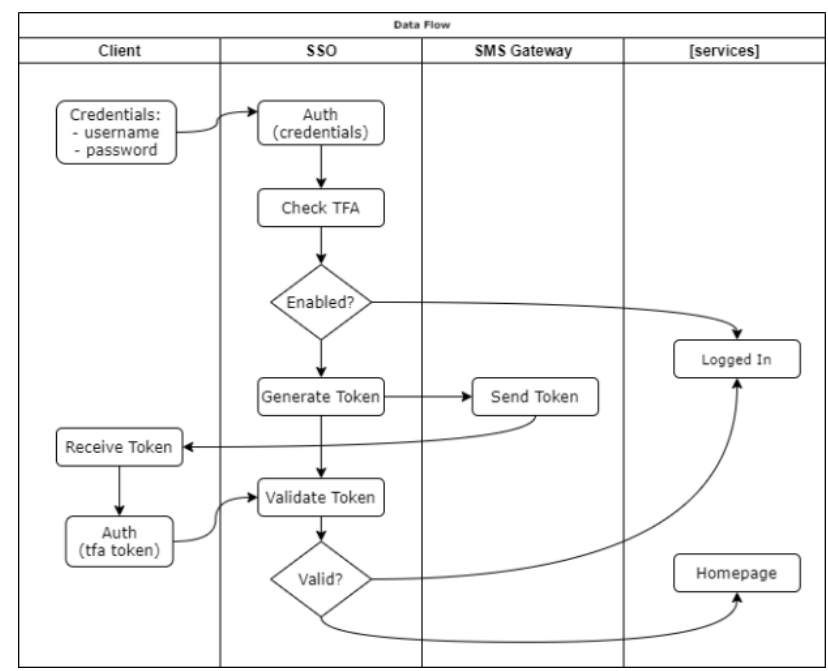

Gambar 3. Data flow diagram

Setelah pengguna mendapatkan token yang telah dikirimkan melalui SMS, pengguna kemudian memasukkan token tersebut kedalam SSO. SSO akan melakukan validasi token pengguna, jika token pengguna berhasil divalidasi SSO kemudian akan membuat sesi login yang baru untuk pengguna yang akan diset pada service atau aplikasi yang dituju oleh pengguna.

\section{Use Case Diagram}

Implementasi TFA pada SSO dikondisikan untuk tidak banyak memberikan dampak terhadap aplikasi yang sudah berjalan. Use case diagram dalam implementasi TFA hanya membutuhkan dua fungsi baru, yakni fitur aktivasi bagi pengguna pada halaman pengaturan dan fungsi 
validasi token TFA yang telah tersimpan pada Session dengan token yang diterima pengguna melalui SMS.

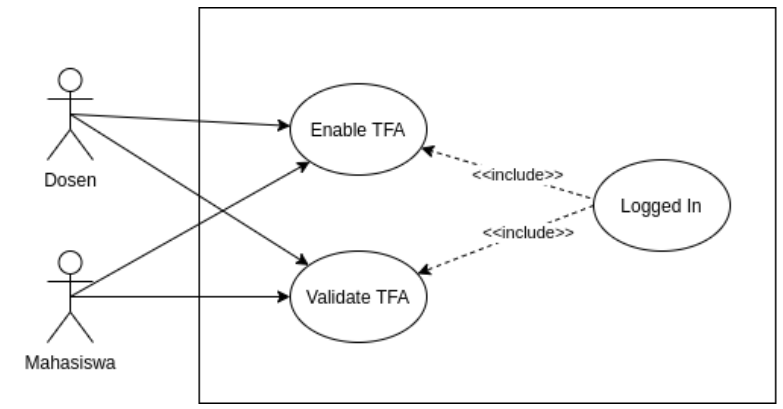

Gambar 4. Use case diagram

\section{SMS Gateway}

Dalam penelitian ini SMS Gateway diperlukan untuk kebutuhan mengirim SMS. SMS Gateway sendiri memiliki arsitektur terpisah, sehingga secara design memungkinkan untuk digunakan pada berbagai keperluan pengiriman SMS.

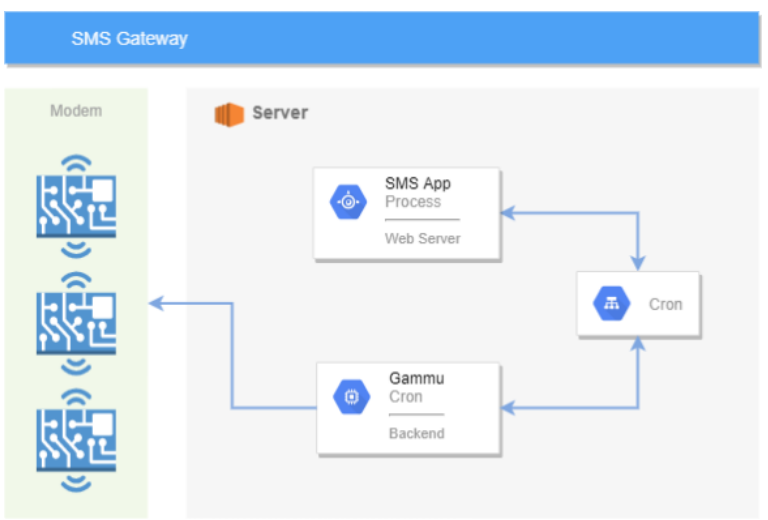

Gambar 5. Arsitektur SMS gateway

Gambar 5 merupakan arsitektur dari SMS Gateway. Bagian terpenting dalam arsitektur ini adalah Gammu. Gammu merupakan software backend yang digunakan dalam penelitian ini agar aplikasi SMS dapat berkomunikasi dengan perangkat modem, dimana nantinya SMS akan diolah didalam SMS Gateway dan dikirimkan melalui perangkat Modem.

Gammu beroperasi layaknya perangkat ponsel, dapat digunakan untuk menerima dan mengirim SMS. Fungsionalitas ini dibuat ulang menjadi software yang dapat dijalankan pada sistem operasi. Gammu saat ini mendukung beberapa jenis sistem operasi, seperti Windows dan Linux. Gammu berkomunikasi dengan perangkat modem menggunakan AT-Command yang merupakan standar komunikasi untuk modem GSM.

Kini pengguna dapat dengan mudah menggunakan Gammu untuk berkirim dan menerima SMS, salah satunya dengan menggunakan database management system seperti MySQL. Pengguna cukup menambahkan row kedalam database untuk mengirim SMS dan membaca SMS cukup dengan membuka data pada database.
Dalam penelitian ini aplikasi yang digunakan adalah SMS Gateway. Fungsionalitas utama untuk pengelolaan SMS telah disediakan dalam versi Application Programming Interface (API), terutama untuk pengiriman SMS. Dengan demikian SSO dengan mudah dapat memanfaatkan fasilitas pengiriman SMS menggunakan aplikasi SMS gateway.

\section{HASIL DAN PEMBAHASAN}

\section{A. Implementasi pada SSO}

Pendekatan umum yang dapat dilakukan dalam implementasi TFA pada SSO adalah menyediakan antar muka yang mudah bagi pengguna. Pada penelitian ini fasilitas untuk mengaktifkan TFA disediakan pada halaman pengaturan yang telah ada sebelumnya pada SIA. Bagian untuk TFA sendiri dipisahkan oleh sebuah blok.

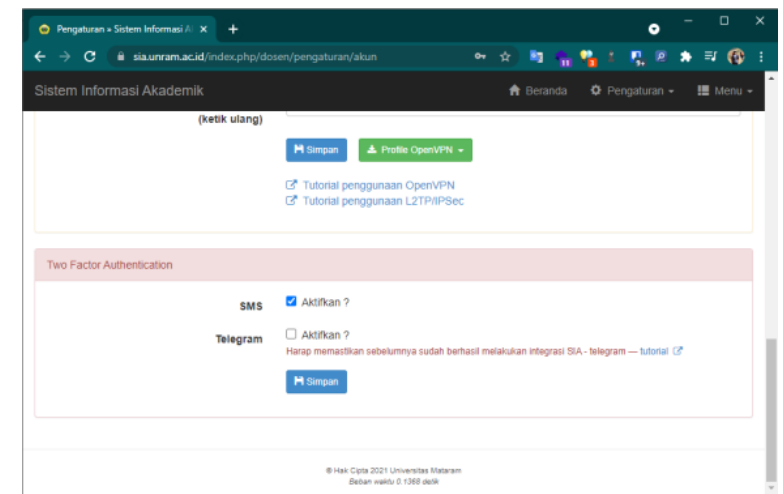

Gambar 6. Halaman pengaturan TFA

Gambar 6 adalah halaman untuk mengaktifkan TFA pada halaman pengaturan di SIA. Pengguna dapat mencentang option SMS untuk mengaktifkan pengiriman token TFA melalui SMS. Setelah memilih opsi, pengguna dapat menyimpan options tersebut dengan menekan tombol simpan.

Perubahan akan terjadi pada siklus login berikutnya. Untuk mengetahui fasilitas TFA telah aktif atau belum, pengguna dapat melakukan logout terlebih dahulu kemudian mencoba untuk login kembali untuk mendapati halaman TFA dan token SMS.
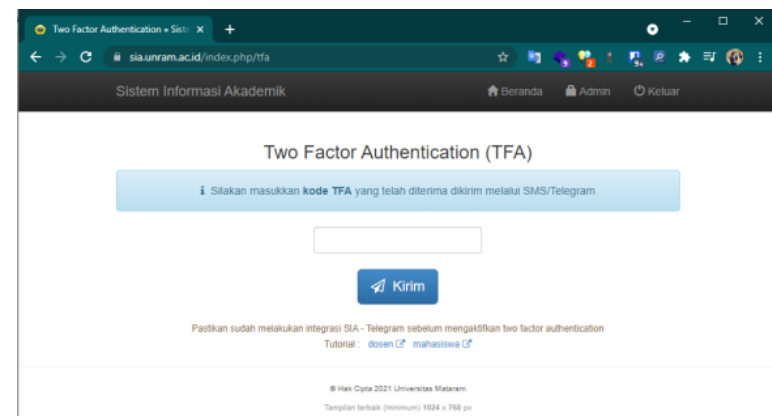

Gambar 7. Halaman mengisi token TFA 
Gambar 7 adalah implementasi tampilan token TFA bagi pengguna yang telah mengaktifkan fitur TFA dan telah berhasil memasukkan username dan password-nya secara benar. Halaman tersebut akan selalu muncul selama pengguna belum memasukkan token TFA yang valid.

Token TFA bersifat acak, akan berbeda pada waktu generate yang satu dengan generate yang lainnya. Generate token bersifat menyeluruh untuk semua pengguna, artinya pengguna kemungkinan besar tidak akan mendapatkan token yang sama meskipun melakukan generate pada waktu yang bersamaan.

Namun demikian mekanisme validasi TFA juga memperhatikan sesi pengguna yang sedang login. Jika seorang pengguna dalam situasi tertentu dapat mengetahui token dari pengguna lainnya, maka token tersebut tidak dapat digunakan untuk login ke pengguna yang bersangkutan.

\section{B. Analisa Serangan Brute Force}

Dalam praktiknya, tool yang banyak digunakan untuk serangan brute force adalah Burp Suite [3]. Skenario serangan dalam penelitian ini, akan diuji percobaan brute force terhadap halaman login SSO.

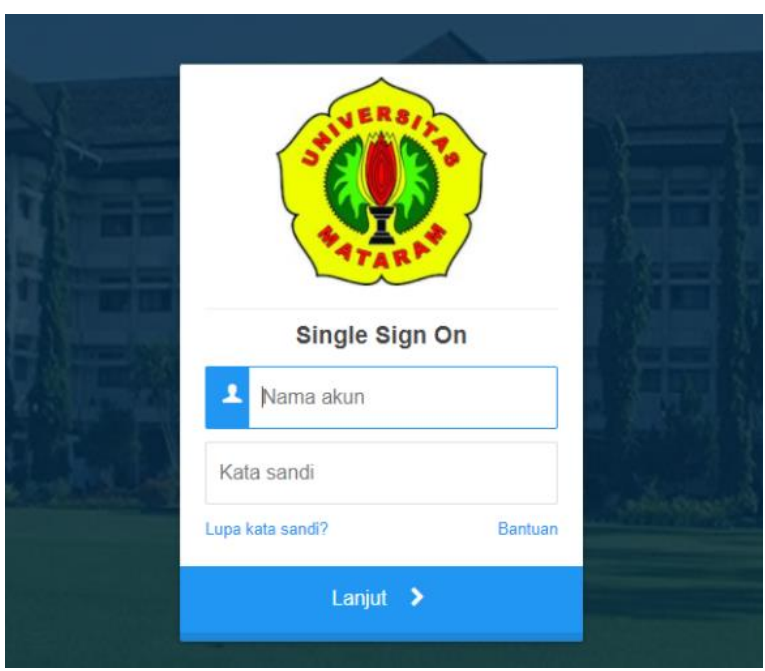

Gambar 8. Halaman login SSO

Traffic intercept adalah fitur yang dapat digunakan sebagai persiapan awal dalam melakukan serangan brute force. Setelah mendapatkan data-data awal seperti nama field dan token sesi jika ada, maka selanjutnya penyerang dapat membuat alur serangan.

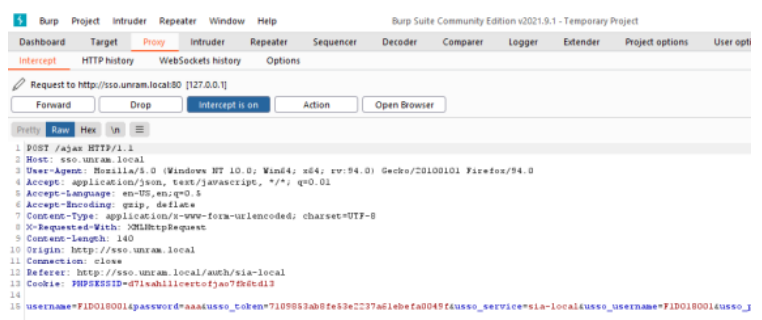

Gambar 9. Masking data awal brute force
Gambar 9 merupakan data awal yang dapat dilakukan masking. Masking dilakukan untuk dapat menjalankan banyak payload secara otomatis. Umumnya masking hanya dilakukan terhadap password saja, username sengaja dibiarkan statis karena target serangan hanya ditujukan kepada satu orang saja. Pada Gambar 9 username yang dijadikan target adalah NIM F1D018001.

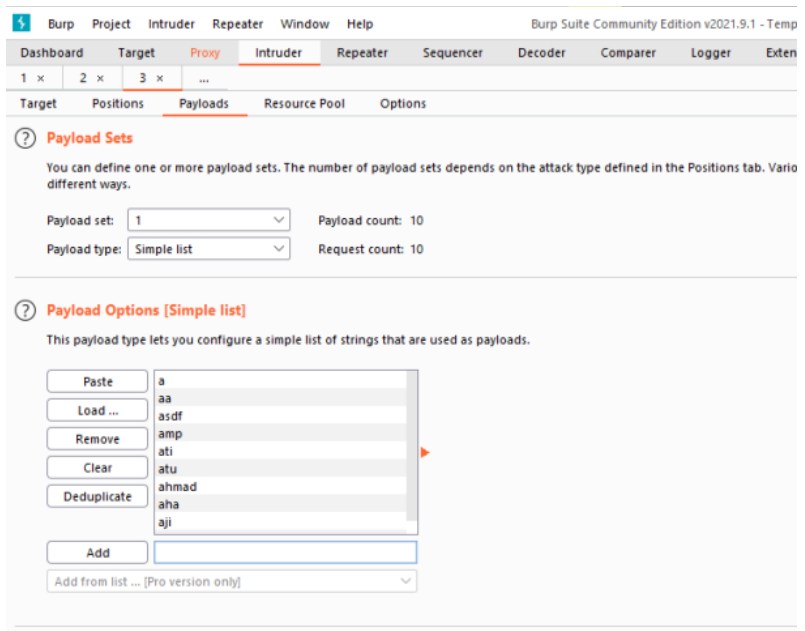

Gambar 10. Daftar kata potensi password

Setelah melakukan masking, penyerang dapat memasukkan daftar kata yang berpotensi untuk digunakan sebagai password. Daftar kata ini tersedia banyak dan mudah untuk ditemukan di internet.

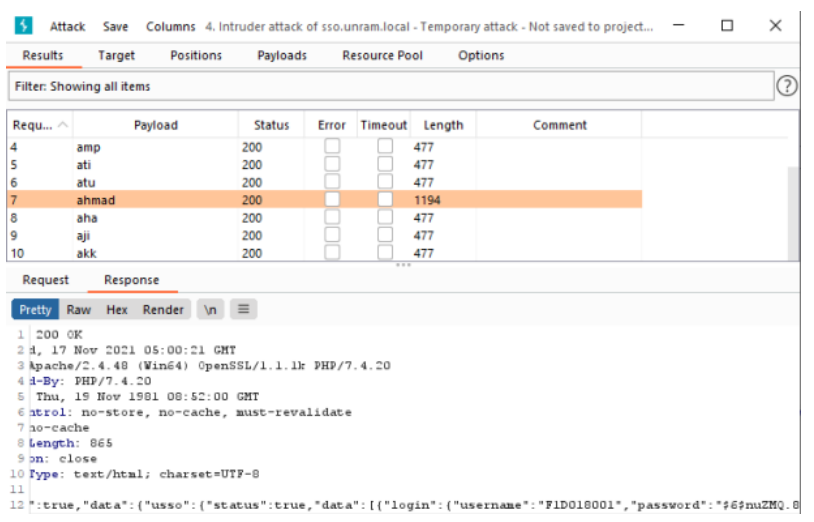

Gambar 11. Hasil dari proses attack

Setelah memasukkan daftar kata dan menjalankannya, penyerang dapat melihat hasil untuk masing-masing kata. Pada gambar diatas kata yang cocok dan menghasilkan informasi true adalah kata "ahmad" yang berarti mahasiswa F1D018001 menggunakan password tersebut.

Pada posisi ini penyerang telah mengetahui username dan password pengguna, kemudian penyerang akan melakukan percobaan login secara normal langsung melalui aplikasi SSO. 


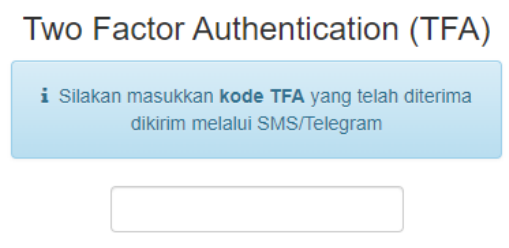

\section{$\triangle$ Kirim}

Pastikan sudah melakukan integrasi SIA - Telegram sebelum mengaktifkan two factor authentication Tutorial : dosen ऍ mahasiswa ऍ

Gambar 12. Halaman TFA setelah berhasil login

Gambar 12 adalah tampilan halaman setelah penyerang memasukkan username dan password yang benar untuk pengguna NIM F1D018001. Dapat terlihat TFA melindungi akses terhadap data pengguna meskipun dengan suatu metode serangan, akun pengguna telah jatuh kepada penyerang.

\section{Analisa Pengalaman Pengguna}

Pengembangan fitur sistem dapat mempengaruhi dua aspek, yakni sisi teknis dan non-teknis. Sisi non-teknis dalam hal ini adalah pengalaman pengguna (user experience) atau yang umum disingkat dengan UX. Tingkat kepuasan pengguna dalam hal penggunaan aplikasi dapat diukur menggunakan User Experience Questionaier (UEQ) [9], [10]. UEQ dapat mengukur tingkat efisiensi, efektivitas, dan kepuasa pengguna terhadap aplikasi atau fitur dalam suatu aplikasi.

Dalam UEQ penilaian dibagi menjadi dua aspek, yakni pragmatis dan hedonis. Aspek kualitas pragmatis adalah persepsi terhadap hal teknis, seperti tampilan, fitur, dan efisiensi. Sedangkan aspek kualitas hedonis cenderung bersifat emosi pengguna, seperti stimulasi untuk menggunakan aplikasi atau fitur dan pengaruh emosi lainnya [15]. Skala penilaian UEQ dapat dilihat pada Tabel I.

TABEL I. Skala Penilaian UEQ

\begin{tabular}{|c|c|c|c|}
\hline No & Category & Value & Scale \\
\hline 1 & Dependability & $\begin{array}{c}\text { menghalangi/ } \\
\text { mendukung }\end{array}$ & Pragmatis \\
\hline 2 & Perspicuity & $\begin{array}{c}\text { rumit/ } \\
\text { sederhana }\end{array}$ & Pragmatis \\
\hline 3 & Efficiency & $\begin{array}{c}\text { tidak efisien/ } \\
\text { efisien }\end{array}$ & Pragmatis \\
\hline 4 & Perspicuity & $\begin{array}{c}\text { membingungkan/ } \\
\text { jelas }\end{array}$ & Pragmatis \\
\hline 5 & Stimulation & $\begin{array}{c}\text { membosankan/ } \\
\text { mengasyikkan }\end{array}$ & Hedonis \\
\hline 6 & Stimulation & $\begin{array}{c}\text { tidak menarik/ } \\
\text { menarik }\end{array}$ & Hedonis \\
\hline 7 & Novelty & $\begin{array}{c}\text { konvensional/ } \\
\text { berdaya cipta }\end{array}$ & Hedonis \\
\hline 8 & Novelty & tazim/ & Hedonis \\
\hline
\end{tabular}

Pengukuran UEQ menggunakan 8 item dengan masingmasing hasil penilaian dari 1 sampai 7 . Penelitian ini menggunakan formulir UEQ untuk mengetahui pengaruh implementasi TFA terhadap SSO kepada 24 responden yang terdiri dari Dosen dan Mahasiswa. Data Raw hasil pengujian UEQ dapat dilihat pada Tabel II.

TABEL II. Data Raw Hasil Pengujian UEQ

\begin{tabular}{|l|l|l|l|l|l|l|l|}
\hline \multicolumn{7}{|c|}{ Items } \\
\hline $\mathbf{1}$ & $\mathbf{2}$ & $\mathbf{3}$ & $\mathbf{4}$ & $\mathbf{5}$ & $\mathbf{6}$ & $\mathbf{7}$ & $\mathbf{8}$ \\
\hline 7 & 7 & 7 & 7 & 7 & 7 & 7 & 7 \\
\hline 6 & 6 & 7 & 7 & 4 & 5 & 7 & 7 \\
\hline 7 & 7 & 7 & 7 & 6 & 7 & 7 & 7 \\
\hline 7 & 7 & 7 & 7 & 7 & 7 & 7 & 7 \\
\hline 6 & 6 & 7 & 6 & 5 & 6 & 6 & 7 \\
\hline 7 & 7 & 7 & 7 & 6 & 6 & 7 & 6 \\
\hline 7 & 7 & 7 & 7 & 7 & 7 & 7 & 7 \\
\hline 6 & 5 & 6 & 6 & 5 & 5 & 6 & 6 \\
\hline 5 & 3 & 4 & 6 & 4 & 5 & 4 & 4 \\
\hline 7 & 7 & 7 & 7 & 6 & 6 & 5 & 6 \\
\hline 6 & 3 & 3 & 6 & 3 & 4 & 3 & 3 \\
\hline 6 & 5 & 7 & 6 & 5 & 6 & 7 & 7 \\
\hline 6 & 5 & 7 & 5 & 5 & 5 & 6 & 7 \\
\hline 7 & 7 & 7 & 7 & 7 & 7 & 7 & 7 \\
\hline 7 & 6 & 6 & 7 & 4 & 6 & 7 & 7 \\
\hline 6 & 5 & 6 & 7 & 7 & 7 & 6 & 7 \\
\hline 6 & 5 & 5 & 5 & 5 & 6 & 6 & 7 \\
\hline 7 & 4 & 3 & 7 & 4 & 6 & 5 & 1 \\
\hline 5 & 6 & 5 & 6 & 4 & 4 & 6 & 6 \\
\hline 7 & 7 & 7 & 7 & 7 & 7 & 7 & 7 \\
\hline 6 & 2 & 3 & 6 & 4 & 4 & 4 & 2 \\
\hline 5 & 2 & 4 & 5 & 4 & 3 & 4 & 3 \\
\hline 5 & 5 & 6 & 3 & 3 & 4 & 5 & 5 \\
\hline 6 & 5 & 5 & 6 & 6 & 6 & 7 & 7 \\
\hline
\end{tabular}

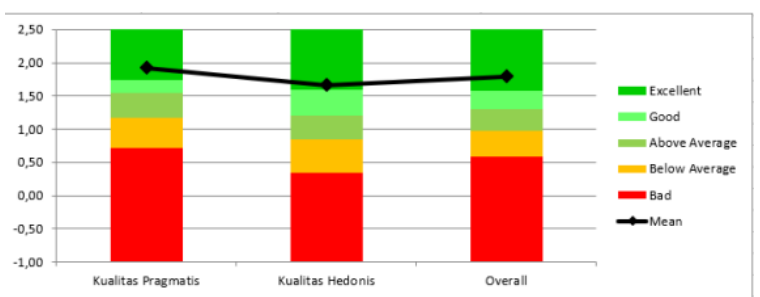

Gambar 13. Benchmark hasil perhitungan UEQ

Gambar 13 merupakan benchmark perhitungan penilaian dari UEQ yang telah disediakan. Masing-masing kualitas aspek memiliki skala yang bervariasi, sesuai dengan data yang tersedia. Secara umum hasil penilaian akhir dari dua skala aspek UEQ mendapatkan nilai excellent. 
TABEL III. HASIL PERHITUNGAN DARi SKala AsPeK Pragmatis DAN HEDONIS

\begin{tabular}{|c|c|c|}
\hline Scale & Mean & Benchmark \\
\hline Pragmatis & 1,927083333 & Excellent \\
\hline Hedonis & 1,666666667 & Excellent \\
\hline Overall & 1,80 & Excellent \\
\hline
\end{tabular}

Tabel III merupakan hasil perhitungan dari skala aspek pragmatis dan hedonis. Penilaian dari skala aspek pragmatis memiliki nilai tertinggi yakni sebanyak 1,93. Tingginya nilai dari aspek pragmatis didukung oleh dua kategori penilaian. Pertama adalah Dependability, yakni pengguna merasa fitur ini mampu mendukung pemanfaatan layanan yang sudah ada. Kemudian pengaruh yang kedua adalah Perspicuity dalam hal penilaian terhadap kejelasan alur fitur yang diberikan, sehingga pengguna tidak merasa kesulitan dalam menggunakan sistem.

Kualitas aspek hedonis mendapatkan nilai 1,67 dan masih tergolong dalam kategori excellent. Nilai dari aspek hedonis cenderung lebih rendah dibandingkan dengan nilai dari aspek pragmatis. Faktor penilaian yang mempengaruhi nilai dari aspek hedonis dalam penelitian ini adalah Stimulation, yakni pengguna tidak cukup termotivasi dalam menggunakan fitur TFA pada SSO. Faktor dalam aspek hedonis yang memberikan porsi penilaian yang besar adalah Novelty, yakni dari sisi inovasi.

Implementasi TFA pada masa ini belum banyak diimplementasikan, diakibatkan oleh kurangnya kesadaran terhadap keamanan informasi. Sehingga dengan tersedianya TFA pada layanan SSO, pengguna dapat merasa lebih aman untuk beraktivitas di dalam sistem.

\section{KESIMPULAN}

1. Pengujian simulasi serangan brute force dengan mengaktifkan fitur TFA pada SSO menunjukkan serangan tidak dapat menembus akun SSO, meskipun username dan password akun sudah diketahui oleh penyerang.

2. Pengujian pengalaman pengguna menggunakan UEQ secara keseluruhan mendapatkan hasil 1,797 atau berada dalam kategori excelent.

3. Dalam aspek pragmatis pengujian mendapatkan hasil paling tinggi yakni 1,927 , kategori penilaian yang berkontribusi besar dalam porsi nilai adalah Dependability dan Perspicuity. Hal ini menunjukkan pengguna merasa fitur ini mampu mendukung pemanfaatan layanan yang sudah ada dan fitur TFA dalam SSO dirasa memiliki alur yang cukup jelas.

4. Dalam aspek hedonis pengujian mendapatkan hasil lebih kecil dibandingkan aspek pragmatis yakni 1,667, namun hasil ini masih dalam kategori excellent. Kategori yang memiliki nilai terendah adalah Stimulation, yakni pengguna masih belum cukup termotivasi untuk memanfaatkan TFA dalam SSO.

\section{REFERENSI}

[1] J. Costa and A. Michalas, "Middle Man: An Efficient TwoFactor Authentication Framework," 2017 Int. Conf. Comput. Commun. Control Autom. ICCUBEA 2017, pp. 1-7, 2018, doi: 10.1109/ICCUBEA.2017.8463686.

[2] K. S. M. Moe and T. Win, "Improved hashing and honeybased stronger password prevention against brute force attack,” 2017 Int. Symp. Electron. Smart Devices, ISESD 2017, vol. 2018-January, pp. 1-5, 2017, doi: 10.1109/ISESD.2017.8253295.

[3] R. Vibhandik and A. Kumar Bose, "Vulnerability assessment of web applications - a testing approach," 2015 Forth Int. Conf. e-Technologies Networks Dev., pp. 16-21, 2015.

[4] S. Binu, M. Misbahuddin, and P. Raj, "A Single Sign on based secure remote user authentication scheme for MultiServer Environments," Int. Conf. Comput. Commun. Technol. ICCCT 2014, 2014, doi: 10.1109/ICCCT2.2014.7066715.

[5] N. R. Chakraborty, M. T. Rahman, M. E. Rahman, and M. S. Uddin, "Generation and verification of digital signature with two factor authentication," IWCI 2016 - 2016 Int. Work. Comput. Intell., no. December, pp. 131-135, 2017, doi: 10.1109/IWCI.2016.7860353.

[6] S. Indu, T. N. Sathya, and V. Saravana Kumar, "A standalone and SMS-based approach for authentication using mobile phone," 2013 Int. Conf. Inf. Commun. Embed. Syst. ICICES 2013, pp. 140-145, 2013, doi: 10.1109/ICICES.2013.6508205.

[7] E. Sediyono, K. I. Santoso, and Suhartono, "Secure login by using One-time Password authentication based on MD5 Hash encrypted SMS," Proc. 2013 Int. Conf. Adv. Comput. Commun. Informatics, ICACCI 2013, pp. 1604-1608, 2013, doi: 10.1109/ICACCI.2013.6637420.

[8] H. Liu and Y. Zhang, "An improved one-time password authentication scheme," Int. Conf. Commun. Technol. Proceedings, ICCT, pp. 1-5, 2013, doi: 10.1109/ICCT.2013.6820340.

[9] M. Schrepp, A. Hinderks, and J. Thomaschewski, "Construction of a Benchmark for the User Experience Questionnaire (UEQ),” Int. J. Interact. Multimed. Artif. Intell., vol. 4, no. 4, p. 40, 2017, doi: 10.9781/ijimai.2017.445.

[10] M. Schrepp, A. Hinderks, and J. Thomaschewski, "Design and Evaluation of a Short Version of the User Experience Questionnaire (UEQ-S)," Int. J. Interact. Multimed. Artif. Intell., vol. 4, no. 6, p. 103, 2017, doi: 10.9781/ijimai.2017.09.001.

[11] A. Derhab, M. Belaoued, M. Guerroumi, and F. A. Khan, "Two-Factor Mutual Authentication Offloading for Mobile Cloud Computing," IEEE Access, vol. 8, pp. 2895628969, 2020, doi: 10.1109/ACCESS.2020.2971024.

[12] G. R. Haron, D. Maniam, L. Mat Nen, and N. I. Daud, "User behaviour and interactions for multimodal 
authentication," 2016 14th Annu. Conf. Privacy, Secur. Trust. PST 2016, pp. 309-316, 2016, doi: 10.1109/PST.2016.7906979.

[13] W. Bin Hsieh and J. S. Leu, "Design of a time and location based One-Time Password authentication scheme," IWCMC 2011 - 7th Int. Wirel. Commun. Mob. Comput. Conf., pp. 201-206, 2011, doi: 10.1109/IWCMC.2011.5982418.

[14] C. Thammarat, W. Kurutach, and S. Phoomvuthisarn, "A secure lightweight protocol for SMS mutual authentication protocols based on symmetic-key encryption," 2017 17th Int. Symp. Commun. Inf. Technol. Isc. 2017, vol. 2018Janua, pp. 1-6, 2017, doi: 10.1109/ISCIT.2017.8261196.

[15] V. Intanny et al., "Pengukuran Kebergunaan dan Pengalaman Pengguna Marketplace Jogjaplaza.id dengan Metode UEQ dan USE Questionnaire Measuring Usability and User Experience of The Marketplace of Jogjaplaza.id Using UEQ and USE Questionnaire,” J. Pekommas, vol. 3, no. 2, pp. 117-126, 2018. 